\title{
Role of Local Air-Sea Interaction in a Significant Correlation of Convective Activity in the Western Pacific Warm Pool between June and August
}

\author{
Feng XUE and Fangxing FAN \\ International Center for Climate and Environment Sciences, Institute of Atmospheric Physics, \\ Chinese Academy of Sciences, China
}

(Manuscript received 11 September 2018, in final form 17 June 2019)

\begin{abstract}
Based on the monthly outgoing longwave radiation (OLR) data from 1979 to 2013, a significant correlation of convective activity over the western Pacific warm pool between June and August was detected, while there were no significant correlations between June and July and between July and August. The analysis results indicate that consistent anomalies in June and August usually occur during the years with strong warm pool convection. Moreover, two prerequisites are necessary for this consistent anomaly, that is, a higher sea surface temperature (SST) over the warm pool during the preceding spring and a relatively weak El Niño and Southern Oscillation (ENSO). An analysis based on the selected typical years indicates that convection in June tends to be enhanced when the warm pool SST is higher in the spring. The enhanced convection, in turn, reduces the solar insolation and local SST and consequently suppresses convection in July. In contrast to June, the local SST tends to increase due to the suppressed convection in July. Accordingly, the warm pool convection in August is subsequently enhanced again. In this process, the local air-sea interaction plays a major role in regulating SST anomalies from June to August and forming the consistent warm pool convection anomalies in June and August. There are additional complications in understanding intraseasonal variations in the warm pool convection from June to August as related to the ENSO forcing. During strong El Niño decaying years (e.g., 1998), the warm pool convection is suppressed with consistent positive OLR anomalies from June to August, implying that the El Niño forcing contributes to the significant positive correlation of convective activity between June and August. During moderate El Niño decaying years (e.g., 2007), however, the convection anomaly in June is opposite to that in August. In general, the local air-sea interaction effect plays an essential role in the significant correlation of convective activity between June and August, although this correlation also depends on the intensity of the El Niño forcing.
\end{abstract}

Keywords warm pool convection; positive correlation; local air-sea interaction; ENSO

Citation Xue, F., and F. Fan, 2019: Role of local air-sea interaction in a significant correlation of convective activity in the western Pacific warm pool between June and August. J. Meteor. Soc. Japan, 97, 995-1008, doi:10.2151/ jmsj.2019-054.

Corresponding author: Feng Xue, International Center for Climate and Environment Sciences, Institute of Atmospheric Physics, Chinese Academy of Sciences, Beijing 100029, China

E-mail: fxue@lasg.iap.ac.cn

J-stage Advance Published Date: 5 July 2019

(C) The Author(s) 2019. This is an open access article published by the Meteorological Society of Japan under a Creative Commons Attribution 4.0 International (CC BY 4.0) license (https://creativecommons.org/licenses/by/4.0). 


\section{Introduction}

During boreal summers, large-scale convective cloud clusters are observed from the South China Sea to the east of the Philippines; these clusters are often referred to as the western Pacific warm pool convection. Climatologically, the warm pool convection begins to intensify gradually after the onset of the South China Sea summer monsoon in late May (Tao and Chen 1987; Lau and Yang 1997; Ding and Liu 2001). In late July, the warm pool convection shifts northeastward suddenly, thus signaling the onset of the tropical western Pacific summer monsoon. Specifically, this shift leads to an anomalous anticyclone in subtropical East Asia and the termination of the Meiyu or Baiu seasons from the Yangtze River basin to Japan (Ueda et al. 1995; Wu 2002). As major characteristics of intraseasonal variations of the East Asian summer monsoon (EASM), the two northward jumps of the western Pacific subtropical high (WPSH), occurring in mid-June and late July, are also associated with the enhanced warm pool convection (Su and Xue 2010).

Many observational studies have shown that the interannual variability of the EASM is also influenced by the warm pool convection. In general, the enhanced (suppressed) convection tends to be associated with an anticyclonic (cyclonic) anomaly in East Asia, generated by a Rossby wave train propagating northward (Nitta 1987; Tsuyuki and Kurihara 1989). This teleconnection pattern between the tropical western Pacific and East Asia is referred to as the Pacific-Japan pattern (Nitta 1987). Lu (2001a) further showed that the zonal displacement of the WPSH is affected by the warm pool convection. The enhanced (suppressed) convection can excite a low-level cyclonic (anticyclonic) anomaly in the subtropical western Pacific, leading to the eastward retreat (westward extension) of the WPSH. Therefore, the warm pool convection plays a crucial role in the EASM variability on intraseasonal and interannual timescales; thus, understanding the mechanism of the warm pool convection is of considerable importance for EASM predictions.

The warm pool convection is generally recognized as being influenced by both local and remote sea surface temperature (SST) anomalies that are regulated by the El Niño and Southern Oscillation (ENSO) phase (Lau and Nath 2009; Wu et al. 2010; Lu and Lu 2014). In La Niña years, when a local SST is higher, the warm pool convection tends to be enhanced through the local air-sea interaction (Xue and Zhao 2017). In El Niño developing summers, the warm pool convection is enhanced through a Gill-type response to positive SST anomalies in the central and eastern Pacific (Lau and Nath 2000; Xue et al. 2018). In El Niño decaying summers, however, the warm pool convection is largely suppressed by eastward-propagating Kelvin waves, which originate from the enhanced convection in the tropical Indian Ocean with a higher SST (Yang et al. 2007; Xie et al. 2009). The warm pool convection is, therefore, suggested to serve as a bridge linking El Niño and the EASM.

The warm pool convection is also affected by the local SST anomaly, which is often involved in the ENSO (Lau and Nath 2009). Lu and Lu (2014) noted that a local SST plays an active role in the warm pool convection and partially offsets the remote effect from the ENSO. Hu and $\mathrm{Wu}$ (2016) found that physical processes are very different between seasonal anomalies and monthly departures from the seasonal mean over the South China Sea and tropical Indian Ocean during the spring to summer seasons. Although the remote forcing plays a major role in the seasonal anomaly, the local air-sea interaction is more pronounced in the monthly mean departure. We also note that because El Niño in the decaying summers has a very strong impact on the warm pool convection, the influences of local air-sea interactions may be overwhelmed by the El Niño forcing in correlation or composite analyses.

In this study, we found a significant correlation of convective activity in the warm pool between June and August, while the correlations between other summer months are relatively weak. As this correlation is independent of the phase of ENSO, it cannot be explained by the ENSO forcing. To address this issue, we conducted a detailed analysis based on the reanalysis data from 1979 to 2013. In Section 2, the monthly correlations of convective activity in the warm pool are described briefly. Some typical examples are further analyzed in Sections 3 and 4 to reveal the underlying physical processes and mechanisms. Finally, a summary is given in the last section.

\section{Data description and monthly correlation of convective activity in the warm pool}

Outgoing longwave radiation (OLR) data are used as a proxy for tropical convection, and are obtained from NOAA satellite observations (Liebmann and Smith 1996). Other datasets include the atmospheric circulation and surface flux data from NCEP-DOE Reanalysis-2 (Kanamitsu et al. 2002) and SST data from NOAA (Smith et al. 2008). The horizontal resolutions of SST, atmospheric circulation (OLR), and surface flux are $2.0^{\circ} \times 2.0^{\circ}, 2.5^{\circ} \times 2.5^{\circ}$, and $1.904^{\circ} \times 1.875^{\circ}$ 
(a)
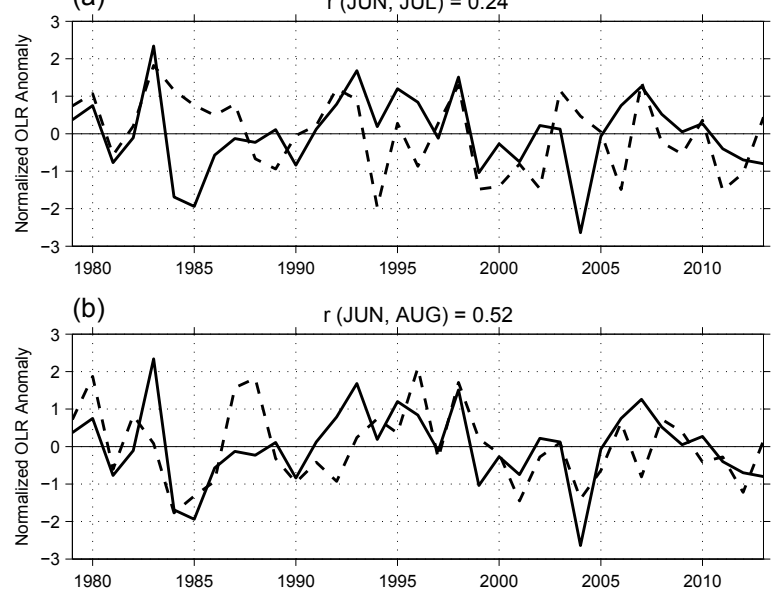

(c)

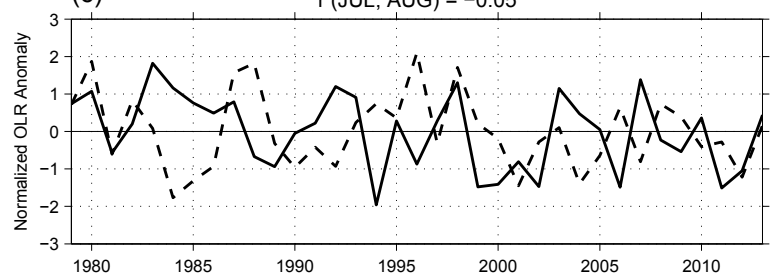

Fig. 1. Normalized outgoing longwave radiation (OLR) anomaly from 1979 to 2013: (a) June (solid) and July (dashed), (b) June (solid) and August (dashed), (c) July (solid) and August (dashed).

latitude/longitude, respectively. Since the OLR data are available only from 1979 to 2013, all datasets were analyzed during this 35-year period for consistency.

Considering the largest interannual variability of convection in the tropical western Pacific, Lu (2001b) defined the warm pool convection as the mean OLR averaged over $\left(110-160^{\circ} \mathrm{E}, 10-20^{\circ} \mathrm{N}\right)$, and a negative (positive) OLR anomaly corresponds to enhanced (suppressed) convection. Figure 1 shows the time series of the normalized OLR anomaly, in which the OLR anomaly series are compared between two different summer months in each subfigure. The correlation coefficients of monthly OLR anomalies between different summer months are remarkably different. The correlation coefficient of monthly OLR anomalies between June and July $(r=0.24)$ is statistically insignificant. By comparison, the correlation between June and August strengthens considerably ( $r$ $=0.52$ ), which is substantially significant at the $99 \%$ confidence level. We also note that the correlation of OLR anomalies between July and August is very weak $(r=-0.05)$ and insignificant, thus indicating the lack of linkage in warm pool convection from July to

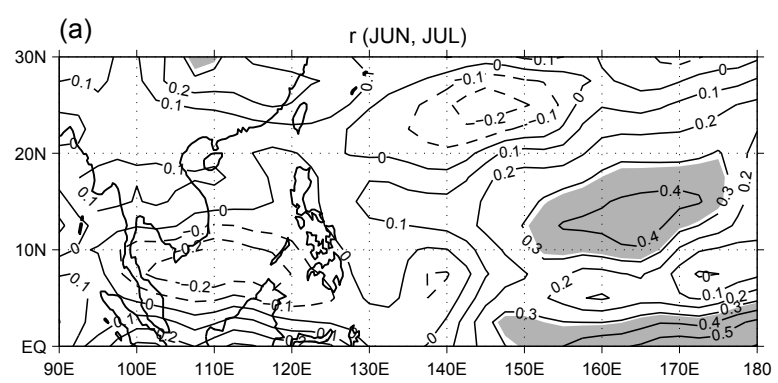

(b)

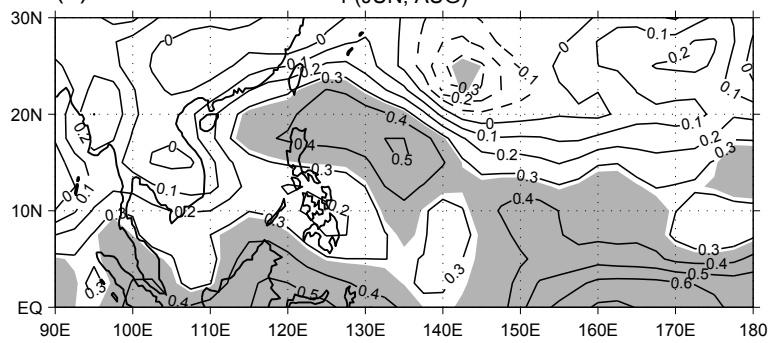

(c)

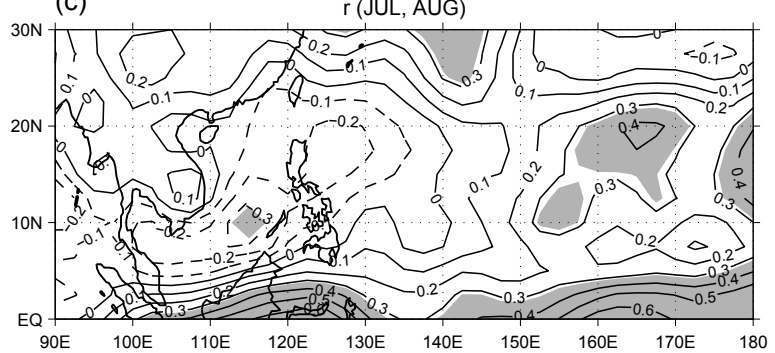

Fig. 2. Correlation coefficient of OLR in the western Pacific; regions with a correlation coefficient above the $95 \%$ confidence level are shaded: (a) June and July, (b) June and August, (c) July and August.

August. The significant positive correlation of convective activity over the warm pool between June and August, despite the weak connections between other summer months, is not yet well understood.

Figure 2 shows the spatial distributions of monthly OLR correlations in the western Pacific. The most significant correlation between June and July is located to the east of $150^{\circ} \mathrm{E}$, while the correlations outside this region are relatively weak (Fig. 2a). The distributions of correlation coefficients between June and August (Fig. 2b) are, to a large degree, different from those in Fig. 2a. Significant correlations are found from the South China Sea to the west of $140^{\circ} \mathrm{E}$, which are connected to the significant correlations near the equator. The spatial pattern of correlations between July and August (Fig. 2c) is somewhat similar to that in Fig. 2a, except in the oceanic region to the south of Japan. In 
general, the spatial distributions of monthly OLR correlations further demonstrate a significant correlation of convective activity over the warm pool between June and August, as illustrated in Fig. 1. We also note that, different from the warm pool region, significant correlations persist from June to August near the equator. This indicates that the physical mechanisms for the correlations in the two regions are different.

Previous studies have shown that the warm pool convection is affected by both local air-sea interactions and the ENSO. While the former plays a major role in the monthly anomaly, the latter is more important to the summer seasonal mean $(\mathrm{Lu}$ and $\mathrm{Lu}$ 2014; $\mathrm{Hu}$ and $\mathrm{Wu} 2016$ ). To distinguish the two factors governing the convection variability on different timescales more clearly, band-pass (30-90 days) and low-pass ( $>90$ days) filters are applied to daily OLR time series, respectively. Figure 3 illustrates the spatial distributions of monthly OLR correlations between summer months based on band-pass data. Evidently, the correlation patterns in the warm pool region are quite different from those in Fig. 2. The correlation between June and July (Fig. 3a) is negative to the north of $10^{\circ} \mathrm{N}$ from the South China Sea to the date line, with three significant centers located in the South China Sea, $135^{\circ} \mathrm{E}$, and $165^{\circ} \mathrm{E}$. By comparison, a significantly positive correlation is found near the equator. The correlation patterns between July and August are very similar to those between June and July (Fig. 3c), except that the correlations to the east of the Philippines are more significant. Both the negative correlations in the warm pool region and the positive correlations near the equator between consecutive summer months (i.e., June and July in Fig. 3a and July and August in Fig. 3c) lead to the substantially significant positive correlations over the entire western Pacific between June and August (Fig. $3 b)$. The correlation coefficients are above 0.8 near the equator and around 0.7 in the warm pool region. It should be noted that the positive correlation in the warm pool region between June and August is caused by the negative correlations between consecutive summer months, which can be attributed to the effect of local air-sea interactions.

Except for the positive correlations near the equator, the correlation distributions based on the low-pass data are dramatically different from the band-pass result (Fig. 4). The correlations between June and July (Fig. 4a) are somewhat similar to the original result in Fig. 2a, but the correlations to the east of the Philippines are more significant, indicating that a weakly positive correlation of convective activity in

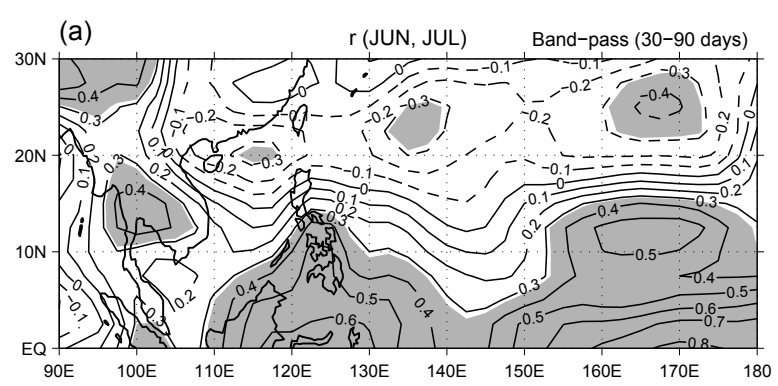

(b)

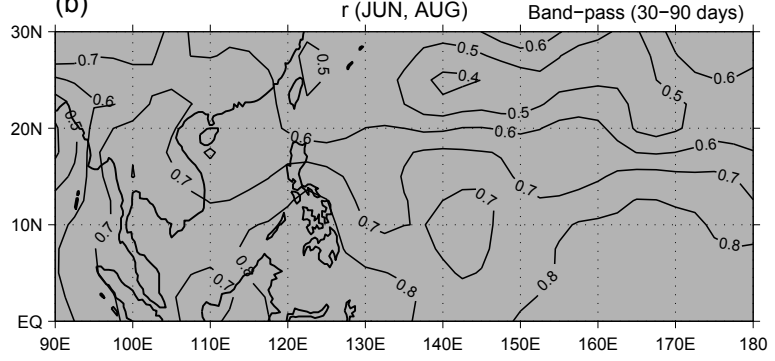

(c)

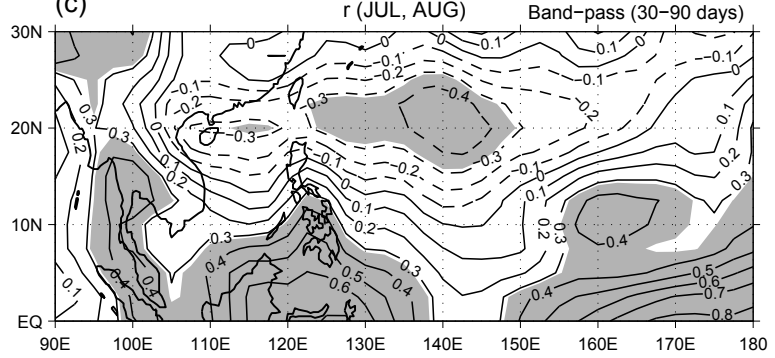

Fig. 3. As in Fig. 2, except for the band-pass filtered data.

the warm pool between June and July $(r=0.24$, Fig. 1a) is mainly related to the ENSO. In addition, the correlation in southern China is also more significant. Similar to the original result (Fig. 2c), the significant correlations between July and August are located mainly in the regions to the east of $150^{\circ} \mathrm{E}$ and to the east of Taiwan, but the correlations in the warm pool region are very weak (Fig. 4c). The correlations between June and August (Fig. 4b) are also weak in all other regions except for the equatorial region, which are quite different from those in Figs. $2 b$ and $3 b$. This implies that the significant correlation of convective activity over the warm pool between June and August $(r=0.52$, Fig. $1 \mathrm{~b})$ is not caused by the ENSO.

A close examination of the OLR anomaly series in Fig. 1b indicates that years with consistent negative OLR anomalies between June and August far exceed those with consistent positive OLR anomalies. Altogether, there are eight years with significant negative anomalies below a -0.5 standard deviation, that is, 
(a)
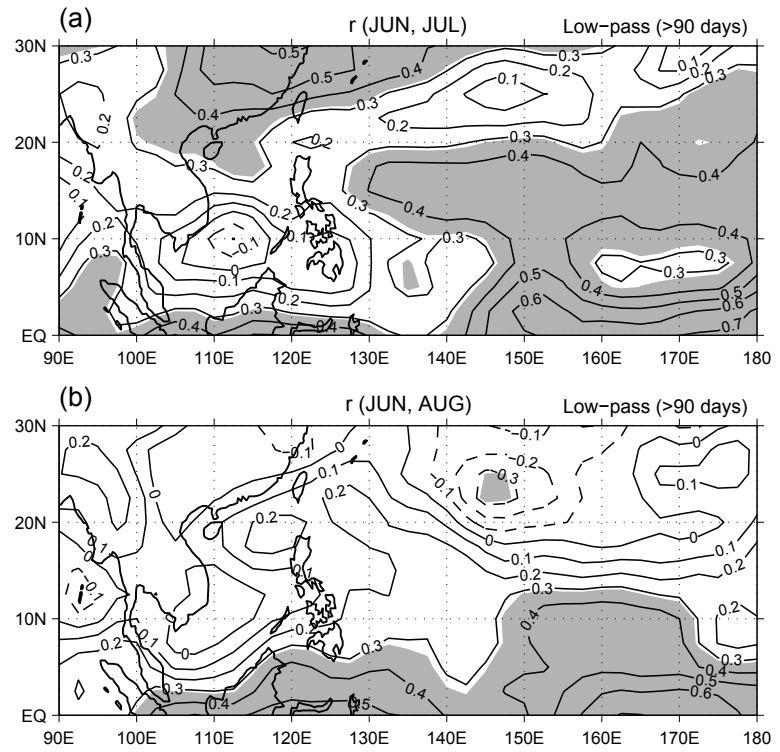

(c)

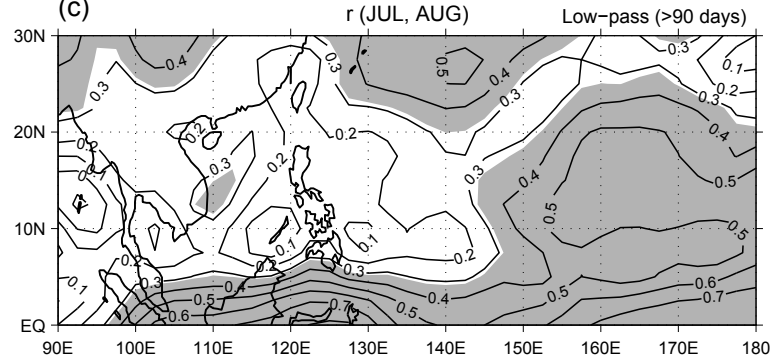

Fig. 4. As in Fig. 2, except for the low-pass filtered data.

1981, 1984, 1985, 1986, 1990, 2001, 2004, and 2012, and the anomaly is below a -1 standard deviation in 1984, 1985, and 2004. By contrast, there are only three years with significant positive anomalies above a 0.5 standard deviation, that is, 1980, 1996, and 1998, in which the anomaly is above a 1 standard deviation only in 1998. Although both the consistent positive and negative anomalies contribute to the positive correlation of OLR anomalies between June and August, the years with negative anomalies play a dominant role. We also note that the consistent positive OLR anomalies in 1980 and 1998 persist throughout the summer from June to August. This implies that the physical mechanism for the negative anomaly is different from that of the positive anomaly. In addition, there is a maximum difference between June and August in 2007, with a positive anomaly in June and a negative anomaly in August. In the following sections, these years are analyzed in detail to reveal the physical mechanism causing the significant correlation

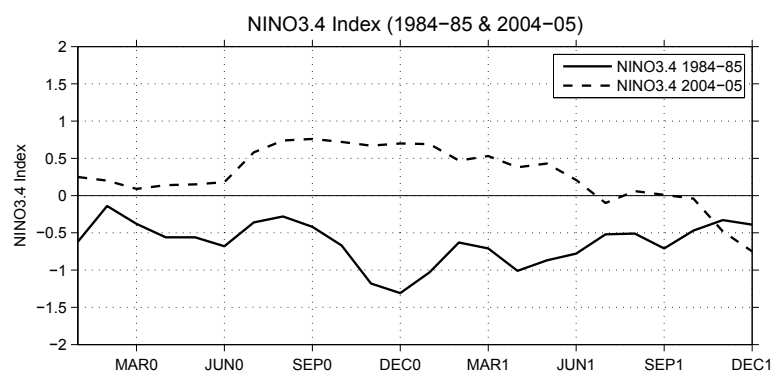

Fig. 5. Niño3.4 Index (unit: ${ }^{\circ} \mathrm{C}$ ) during 1984-85 (solid) and 2004-05 (dashed).

between June and August.

\section{Intraseasonal variation of the warm pool convection in 1984 and 2004}

As stated in the previous section, the strongest warm pool convection in June and August occurred in three years (i.e., 1984, 1985, and 2004). Since 1985 is similar to 1984 , except for a slightly stronger La Niña signal, 1984 and 2004 were selected as the typical examples for an intercomparison. As shown in Fig. 5, 1984 was a La Niña year and 2004 was an El Niño developing year. As the absolute value of the monthly Niño3.4 Index is less than $1^{\circ} \mathrm{C}$ from winter to summer during these two years, we may infer that the warm pool convection is not heavily influenced by the ENSO forcing. The SST anomalies in the spring seasons of 1984 and 2004 share a common feature of a higher SST to the east of the Philippines (Fig. 6), thus indicating that the warm pool SST anomaly is not entirely dependent on the ENSO phase. Nonetheless, there are still some differences in the spring SST anomaly between these two years at a regional scale. While positive SST anomalies extend all over the western Pacific in 2004, negative SST anomalies appear over the East China Sea and the equatorial central Pacific in 1984 due to the La Niña forcing.

A higher SST in the preceding spring provides a favorable thermal condition for the convection's development in June. Figures $7 \mathrm{a}$ and $7 \mathrm{~b}$ illustrate that negative OLR anomalies (enhanced convection) over the warm pool in June of 1984 and 2004, respectively, coincide with positive SST anomalies in the preceding spring (Fig. 6). Moreover, due to a higher warm pool SST in the spring of 2004 than that in the spring of 1984, the OLR anomalies in June 2004 extend farther eastward with a minimum lower than $-40 \mathrm{~W} \mathrm{~m}^{-2}$. Therefore, a positive SST anomaly in the preceding spring plays a major role in triggering the convection 

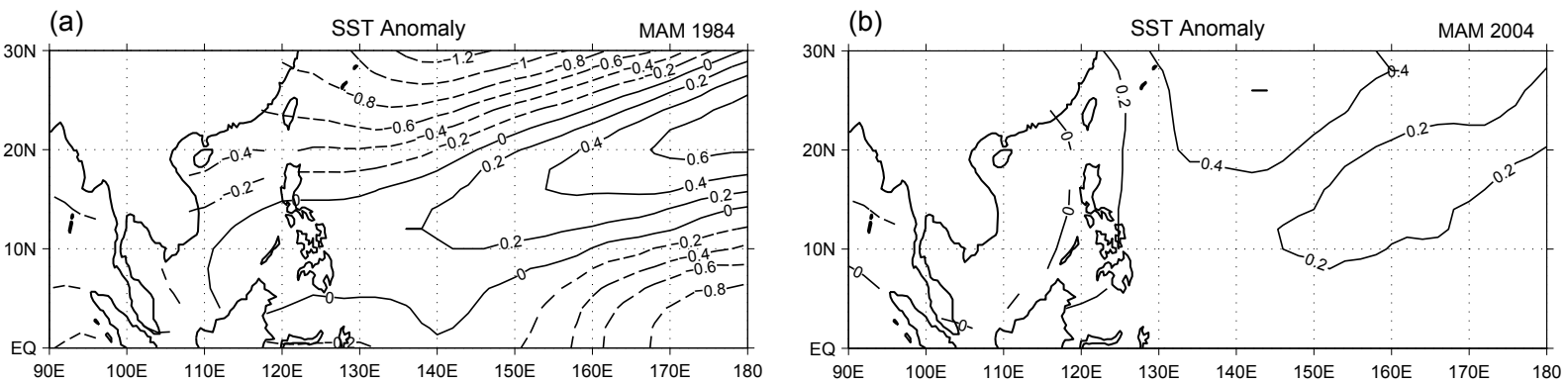

Fig. 6. Sea surface temperature anomaly (unit: ${ }^{\circ} \mathrm{C}$ ) in spring: (a) 1984, (b) 2004.

(a)

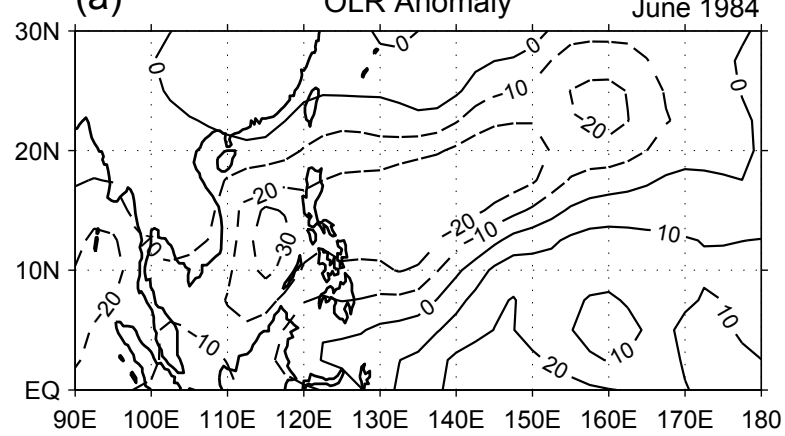

(c)

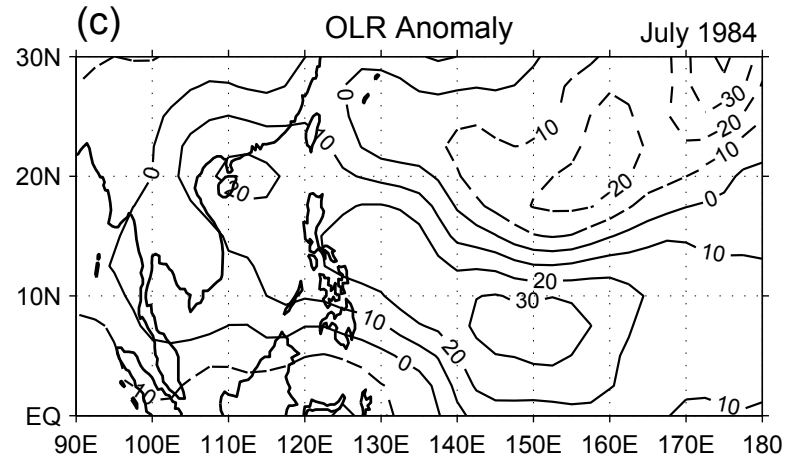

(b)

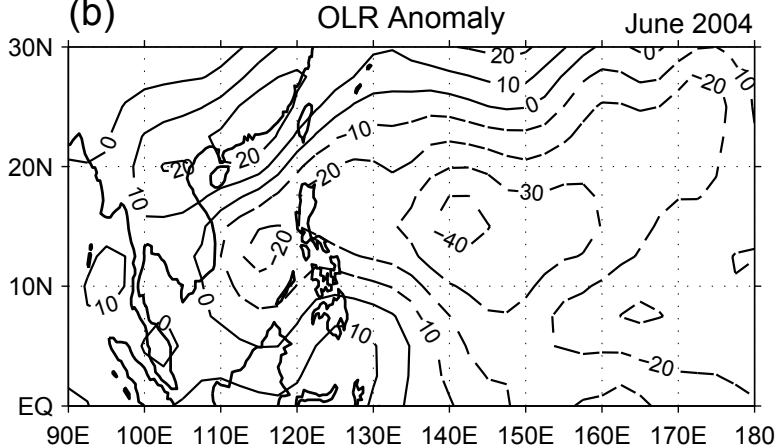

(d)

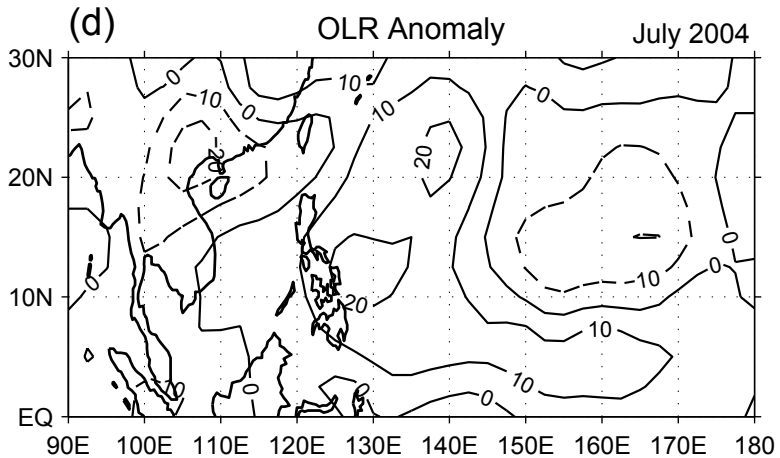

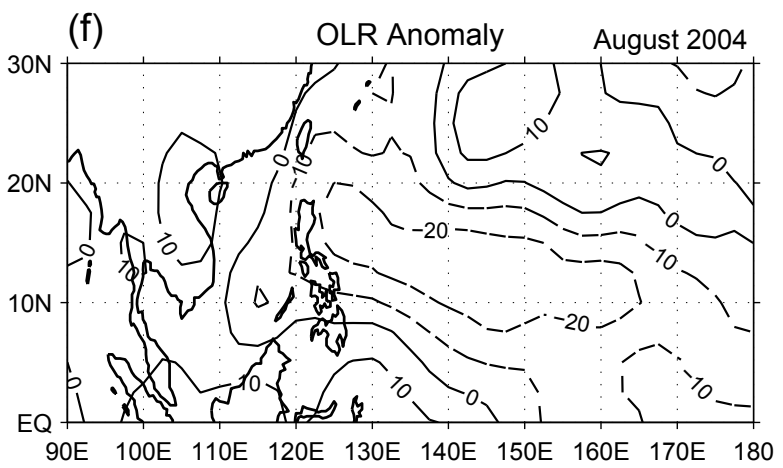

Fig. 7. Monthly mean OLR anomaly (unit: $\mathrm{W} \mathrm{m}^{-2}$ ) in 1984 (left panel) and 2004 (right panel): (a) June 1984, (b) June 2004, (c) July 1984, (d) July 2004, (e) August 1984, (f) August 2004. 
development in the following June.

The enhanced warm pool convection and the greater associated cloud cover lead to decreased solar radiation at the surface. In June of 1984 and 2004 (Figs. 8a, b), significant negative downward solar radiation flux anomalies are found from the South China Sea to the east of the Philippines. The solar radiation flux anomaly patterns evidently resemble OLR anomaly patterns, thus confirming the essential role of the cloud-radiation effect in the monthly SST change. Reduced solar radiation results in a decreased local SST ( $\mathrm{Lu}$ and $\mathrm{Lu}$ 2014; $\mathrm{Hu}$ and $\mathrm{Wu}$ 2016). As shown in Fig. 9, negative SST anomalies from the South China Sea to $150^{\circ} \mathrm{E}$ are approximately $-0.2^{\circ} \mathrm{C}$, with regional anomalies reaching $-0.4^{\circ} \mathrm{C}$ to $-0.6^{\circ} \mathrm{C}$. We note that the SST anomaly value in the South China Sea exceeds that to the east of the Philippines because deep convection in June is located mainly in the South China Sea and the convection to the east of the Philippines is not developed fully. By comparison, the SST anomalies over regions to the east of Taiwan and to the east of $150^{\circ} \mathrm{E}$ are opposite in these two years, which resemble their counterparts in spring (Fig. 6). This implies that the SST anomalies outside (a)

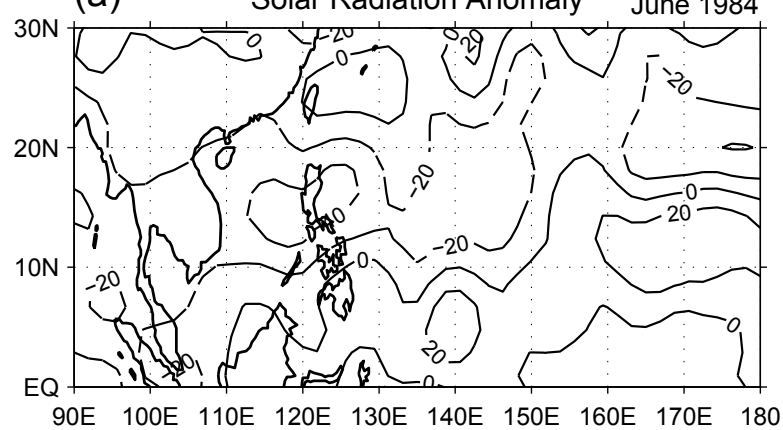

(b)

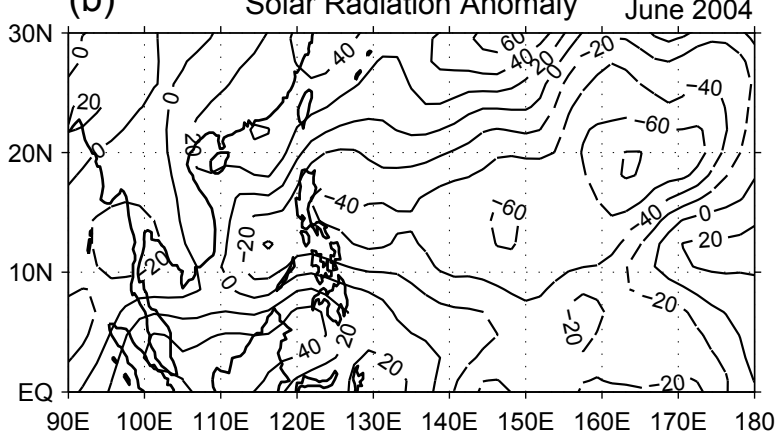

(d)

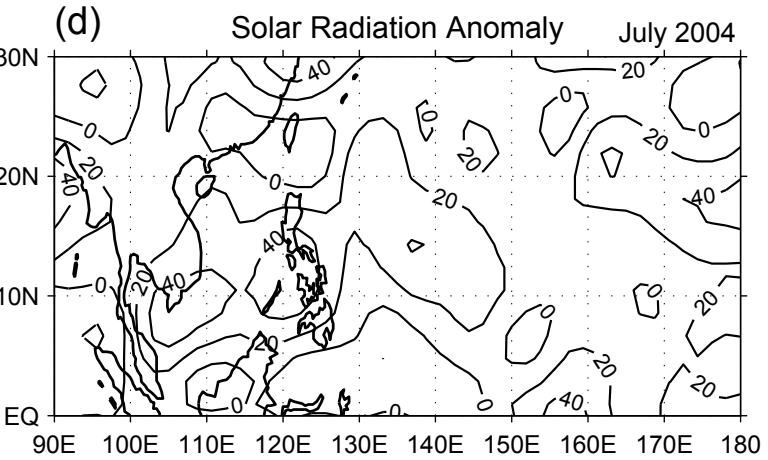

(f) Solar Radiation Anomaly August 2004

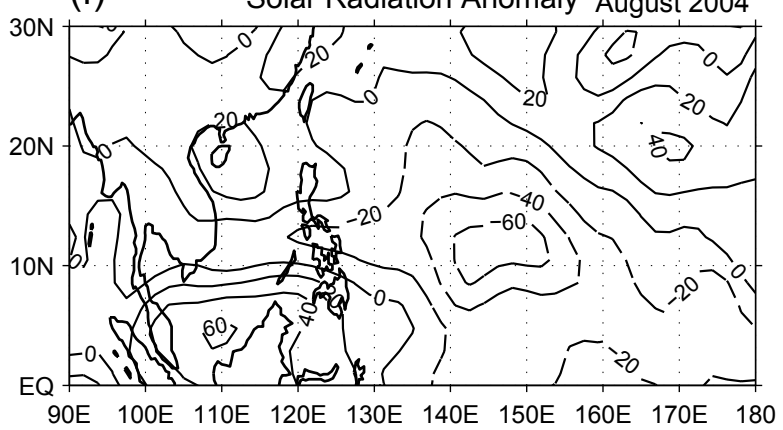

Fig. 8. Monthly mean of downward solar radiation flux anomaly at the surface (unit: $\mathrm{W} \mathrm{m}^{-2}$ ) in 1984 (left panel) and 2004 (right panel): (a) June 1984, (b) June 2004, (c) July 1984, (d) July 2004, (e) August 1984, (f) August 2004. 


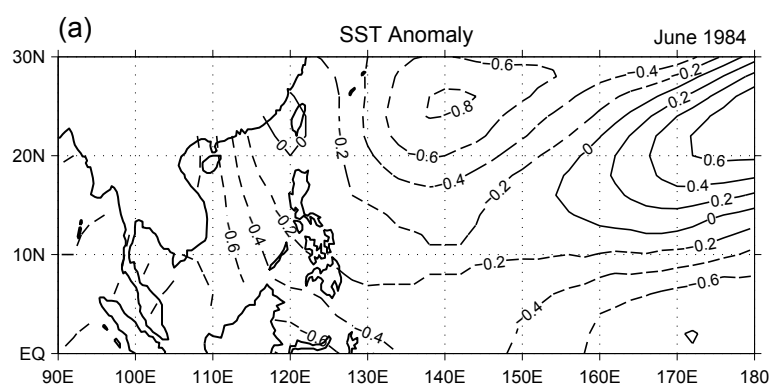

(b)

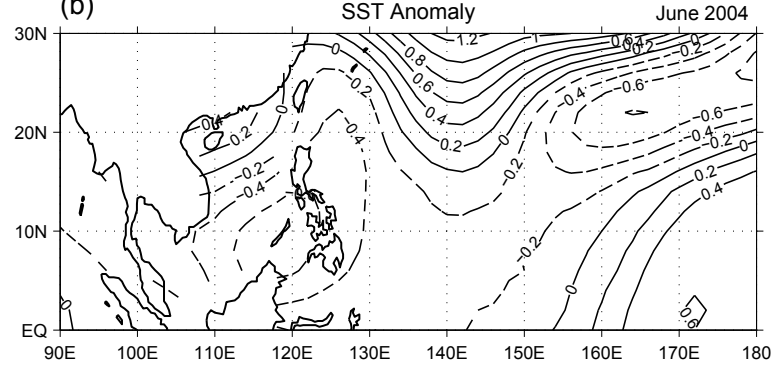

Fig. 9. Sea surface temperature anomaly (unit: ${ }^{\circ} \mathrm{C}$ ) in June: (a) 1984, (b) 2004.

the warm pool are possibly influenced by the ENSO signal and are less related to the local convection development.

Corresponding to negative SST anomalies in June, the warm pool convection in July is suppressed with positive OLR anomalies in both years, except that the OLR anomaly center in 1984 is located more southward than that in 2004 (Figs. 7c, d). Contrary to the June convection, the suppressed convection in July is associated with less cloud cover, which further induces an increased solar radiation at the surface. As shown in Figs. 8c and 8d, the solar radiation tends to intensify in July over the warm pool region. Consequently, the SST to the east of the Philippines tends to rise apparently with an amplitude of $0.5^{\circ} \mathrm{C}$ from June to July (Figs. 10a, b). Over the South China Sea in 1984, a decrease in SST is still evident due to excessive convection development in June (Fig. 7a). We note that a prominent increase in SST to the north of $20^{\circ} \mathrm{N}$ results from the annual cycle from June to July and is entirely unrelated to the warm pool convection. As there is a lower SST in June 1984 and a higher SST in June 2004 (Fig. 9), the former undergoes a more evident increase in SST than the latter (Figs. $10 a, b)$.

In response to an SST increase in the warm pool, the warm pool convection is enhanced again with negative OLR anomalies in August (Figs. 7e, f). Like
June, the major negative OLR anomalies in August 1984 are located from the South China Sea to $140^{\circ} \mathrm{E}$ (Fig. 7e). In August 2004, the negative OLR anomalies extend southeastward to the equator. We stress that the OLR anomaly pattern near the equator in August 2004 resembles that in an El Niño developing August, which is related to the SST anomaly in the central Pacific due to the El Niño development (Xue et al. 2018). Similar to the case in June, the enhanced convection in August leads to a decrease of the solar radiation at the surface, especially from the South China Sea to the east of the Philippines (Figs. 8e, f), thus inducing a decrease in SST in August once more (Figs. 10c, d). While the major negative SST difference is located to the east of Taiwan in 1984 with a minimum of $-1.0^{\circ} \mathrm{C}$, it is generally confined to the west of $150^{\circ} \mathrm{E}$ in 2004 . Like the change from June to July, the SST difference is not exactly in agreement with the negative OLR anomaly center.

In summary, a significant correlation of convective activity over the warm pool between June and August results mainly from the local air-sea interaction. When the warm pool SST is higher in spring, convection in June tends to be enhanced together with a decrease in SST. In turn, convection in July is suppressed due to a decreased SST. Conversely, the suppressed convection in July leads to an increase in SST. Accordingly, convection in August is enhanced once again. During this process, the warm pool convection in June is positively correlated with that in August. We emphasize that this phenomenon is evident only in the warm pool extending from the South China Sea to $150^{\circ} \mathrm{E}$, where a deep convective system is observed in summer. In the equatorial zone to the east of $150^{\circ} \mathrm{E}$, however, OLR maintains a positive anomaly from June to August due to a lower SST associated with the 1984 La Niña event (Fig. 7, left panel). This consistent anomaly is reflected clearly in the monthly OLR correlation (Fig. 2 ), which is in accordance with previous results (Xue and Zhao 2017).

Contrary to positive SST anomalies in spring, there are negative SST anomalies in summer over the warm pool due to enhanced convection especially in June and August (Fig. 11). Since convection develops earliest in the South China Sea, a lower SST is evident there in 1984 and 2004. Like the SST anomaly in June (Fig. 9), the SST anomalies to the east of $150^{\circ} \mathrm{E}$ near the equator are almost opposite between the two years. In addition to local air-sea interactions, the SST anomalies in the tropical western Pacific, especially outside the warm pool, are also affected by the La Niña in 1984 and El Niño in 2004. 
(a)

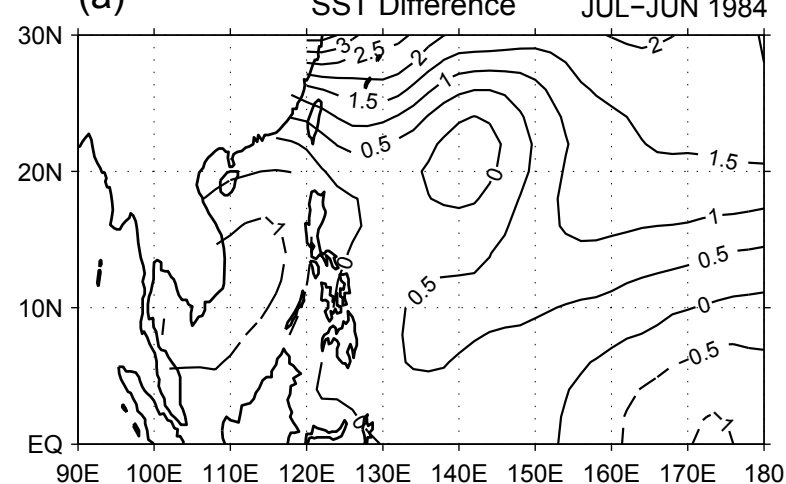

(c)

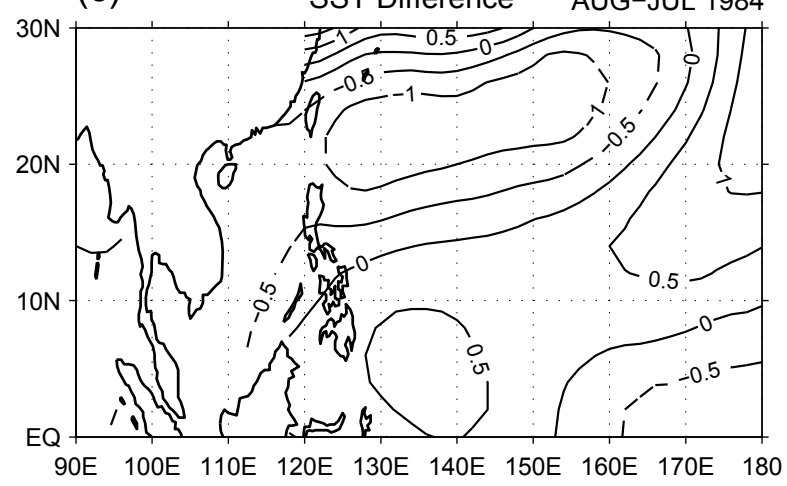

(b) SST Difference JUL-JUN 2004

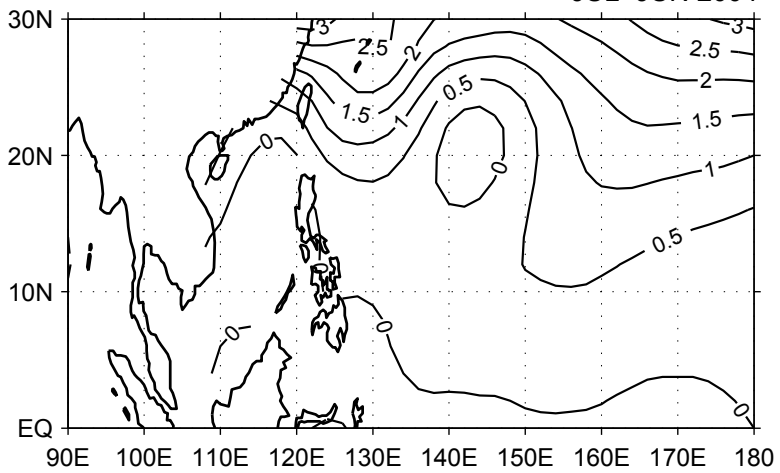

(d)

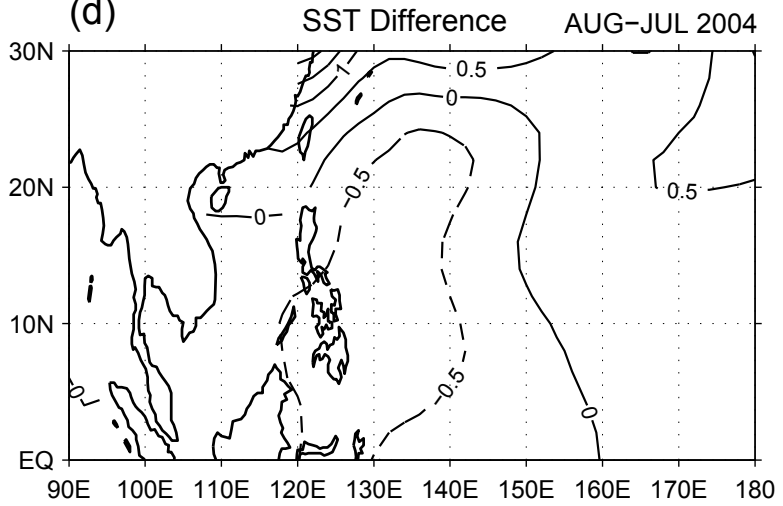

Fig. 10. Monthly sea surface temperature difference (unit: ${ }^{\circ} \mathrm{C}$ ): (a) July minus June in 1984, (b) July minus June in 2004, (c) August minus July in 1984, (d) August minus July in 2004.

The enhanced convection is associated with more precipitation in the warm pool. Lu and Lu (2014) classified the summers of 1984 and 2004 over the warm pool into a climate type characterized by a negative SST anomaly and a positive precipitation anomaly and attributed this SST-precipitation relationship to the atmospheric forcing. However, our analysis results suggest that convection development in June actually originates from a higher SST in the preceding spring, while the atmospheric forcing plays a major role in the intraseasonal shift of the OLR anomaly from June to July. Therefore, not only the concurrent summer SST anomaly but also the preceding spring SST anomaly must be taken into consideration to fully interpret the warm pool convection anomaly.

\section{Competing effects on the warm pool convection in 1998 and 2007}

In addition to the consistent negative OLR anomalies in June and August discussed previously, there are consistent positive OLR anomalies (suppressed warm
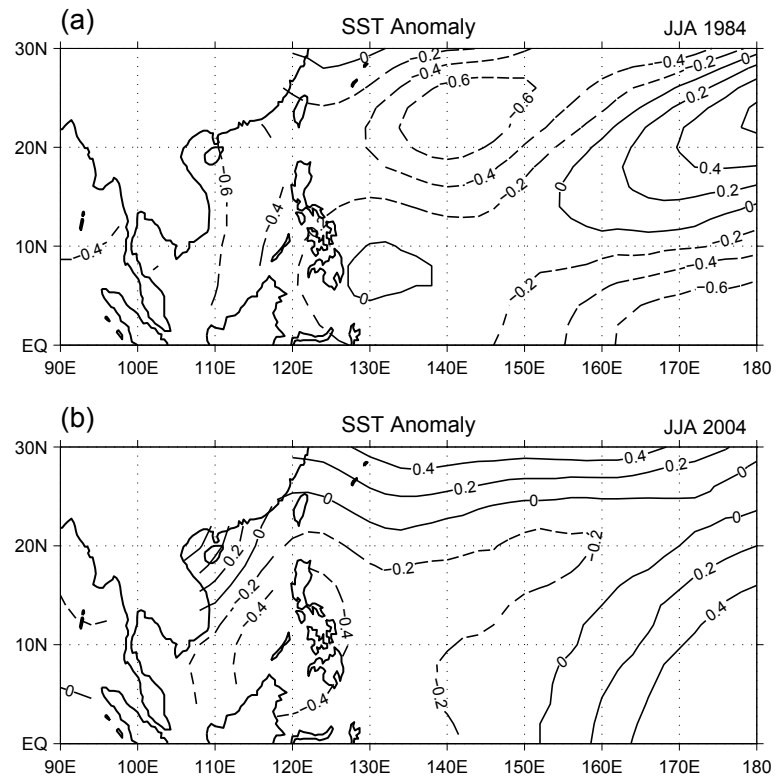

Fig. 11. Sea surface temperature anomaly (unit: ${ }^{\circ} \mathrm{C}$ ) in summer: (a) 1984, (b) 2004. 
pool convection) in some years. The most significant positive anomalies are found in 1998, when the OLR anomalies in June and August exceed a 1 standard deviation (Fig. 1b). The OLR difference between June and August reaches a maximum in 2007 during the 1979-2013 period, with a positive anomaly in June and a negative one in August. To further understand the significant correlation of convective activity in the warm pool between June and August from a different viewpoint, we select 1998 and 2007 for a comparison with the result in Section 3.

The Niño3.4 Index indicates that both 1998 and 2007 are El Niño decaying years, except that the El Niño intensity in 1998 is much stronger than that in 2007 (Fig. 12). The maximum of the monthly Niño3.4 Index during the 1997-1998 El Niño event exceeds $2.0^{\circ} \mathrm{C}$, while that during the $2006-2007$ event is approximately $1.0^{\circ} \mathrm{C}$. Furthermore, the El Niño event in 1998 decays more rapidly and changes to a La Niña state in summer. The Niño3.4 Index in August 1998 is below $-1.0^{\circ} \mathrm{C}$, whereas it is around $-0.5^{\circ} \mathrm{C}$ in the summer of 2007. Due to the influence of El Niño, there is a consistently higher SST over the Indian Ocean from the El Niño mature winter to the decaying summer. During the decaying spring, positive SST anomalies are evident in the tropical Indian Ocean, and the anomaly in 1998 is more prominent than that in 2007 due to the difference in El Niño intensity (Fig. 13). Some discrepancies are found at a regional scale. While positive and negative SST anomalies are seen in the Bay of Bengal and to the east of the Philippines, respectively, in the spring of 1998, the opposite SST anomalies appear over these regions in the spring of 2007.

Previous studies showed that, during an El Niño decaying summer, the warm pool convection is suppressed by Kelvin waves propagating eastward from enhanced convection in the tropical Indian Ocean (Xie et al. 2009; Wu et al. 2010). As illustrated in Fig. 14, the warm pool OLR maintains positive anomalies in June and July for both years. In August, the OLR in 2007 shifts to a negative anomaly, while a positive anomaly persists in 1998.

The difference in the warm pool OLR anomaly in August between 1998 and 2007 can be attributed to the competing effects of the El Niño forcing and local air-sea interactions. As the El Niño intensity in 2007 is much weaker than that in 1998, the convection anomaly over the Indian Ocean in August 2007 is weaker than that in August 1998 (Figs. 14e, f). Furthermore, the warm pool SST tends to rise with the suppressed convection from June to July. The monthly

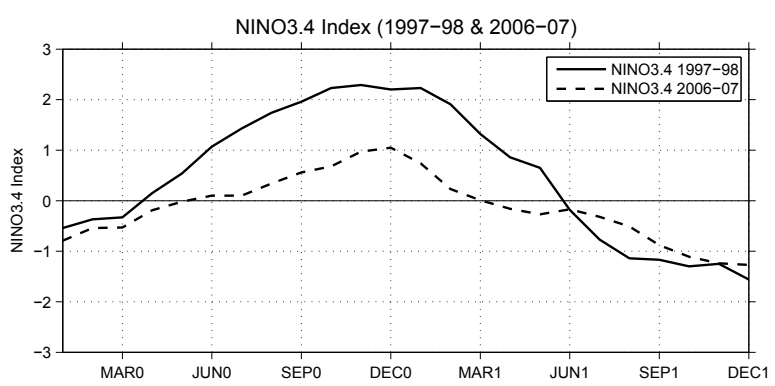

Fig. 12. Niño3.4 Index (unit: ${ }^{\circ} \mathrm{C}$ ) during 1997-98 (solid) and 2006-07 (dashed).
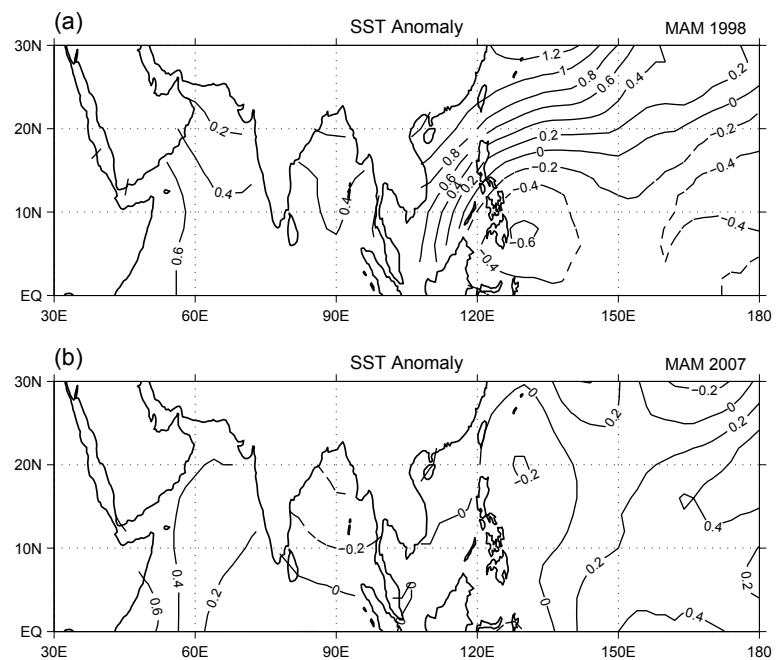

Fig. 13. Sea surface temperature anomaly (unit: ${ }^{\circ} \mathrm{C}$ ) in spring: (a) 1998, (b) 2007.

difference in SST indicates an increase in SST to the east of the Philippines from June to July, with a larger increase in 1998 (Figs. 15a, b). With an SST increase in July and a weaker forcing from the Indian Ocean in August 2007, the warm pool OLR shifts to a negative anomaly due to the local air-sea interaction (Fig. 14f). Accordingly, the warm pool SST decreases from July to August (Fig. 15d). This process is similar to those in 1984 and 2004, as shown in Section 3. By contrast, the warm pool SST continues to rise from July to August because of a stronger forcing from the Indian Ocean in 1998 (Fig. 15c).

A comparison between these two years implies a complex relationship between El Niño and the JuneAugust correlation of convective activity in the warm pool. When the El Niño is very strong, as in 1998, the consistent positive OLR anomalies persist from June 

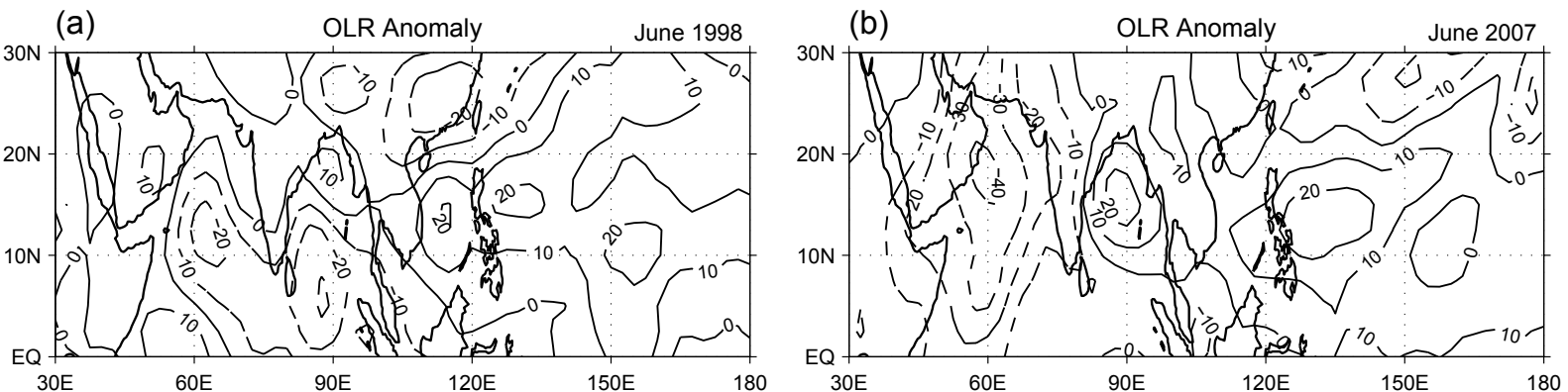

(c) OLR Anomaly

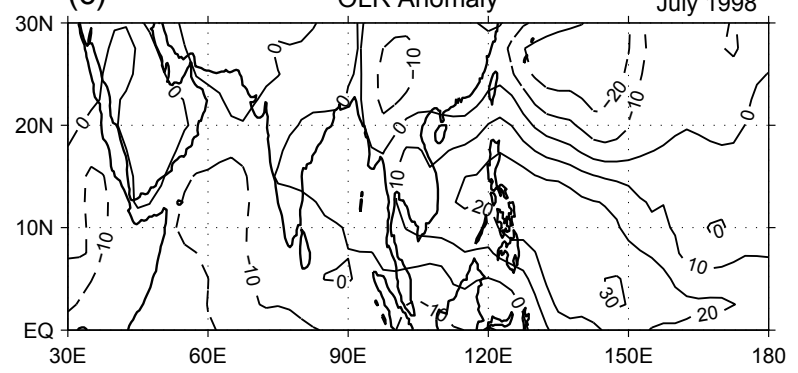

(e)

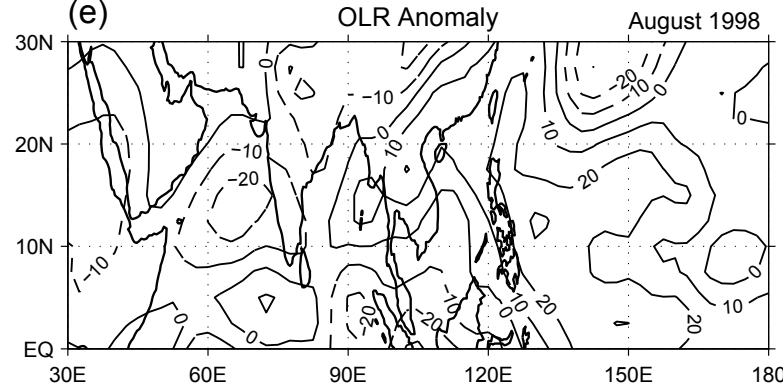

(d) OLR Anomaly

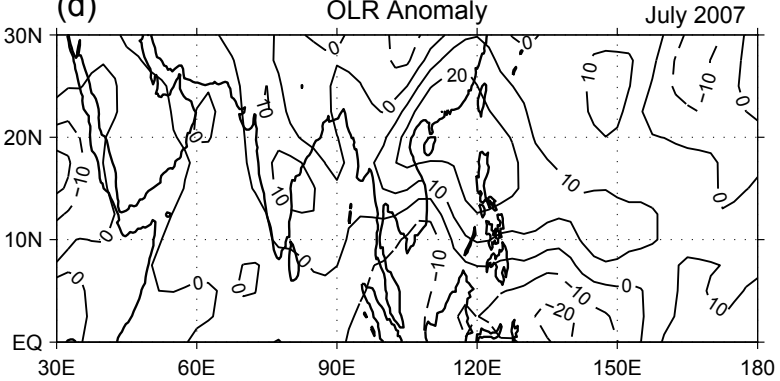

Fig. 14. Monthly mean OLR anomaly (unit: $\mathrm{W} \mathrm{m}^{-2}$ ) in 1998 (left panel) and 2007 (right panel): (a) June 1998, (b) June 2007, (c) July 1998, (d) July 2007, (e) August 1998, (f) August 2007.

to August, and the El Niño forcing plays a positive role in the significant correlation between June and August. When the El Niño is not strong, as in 2007, the effect of local air-sea interactions dominates over the El Niño forcing to determine the convection anomaly in the late summer. The aforementioned results indicate that the effect of local air-sea interactions on the warm pool convection is evident only when the El Niño signal is not strong. Likewise, in strong La Niña years, as in 1989 and 1999, there is no consistent anomaly of the warm pool convection between June and August (Fig. 1b). In this case, the warm pool convection is directly dominated by the La Niña forcing, although the warm pool SST is higher in the preceding spring (Xue and Zhao 2017).

\section{Summary}

Based on the monthly OLR data from 1979 to 2013, we found a significant positive correlation of convective activity over the warm pool between June and August. Years with consistent negative OLR anomalies (i.e., the enhanced warm pool convection) in June and August play a dominant role in this correlation. Two prerequisites are essential for this significant correlation, that is, a higher SST in the preceding spring over the warm pool and a relatively weak ENSO signal. The former provides a thermal condition for the convection development in June, while the latter ensures that the warm pool convection is less affected by the ENSO. A correlation analysis based on bandpass and low-pass filtered data further demonstrates that the ENSO is not a major factor in this June- 
(a)

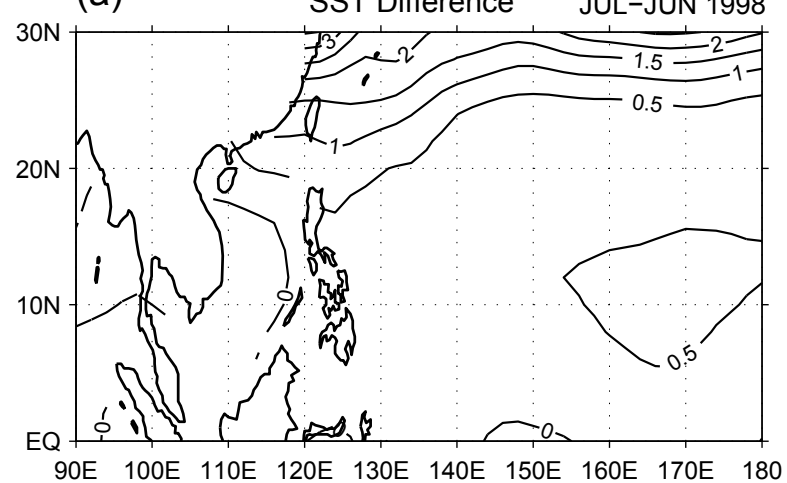

(c)

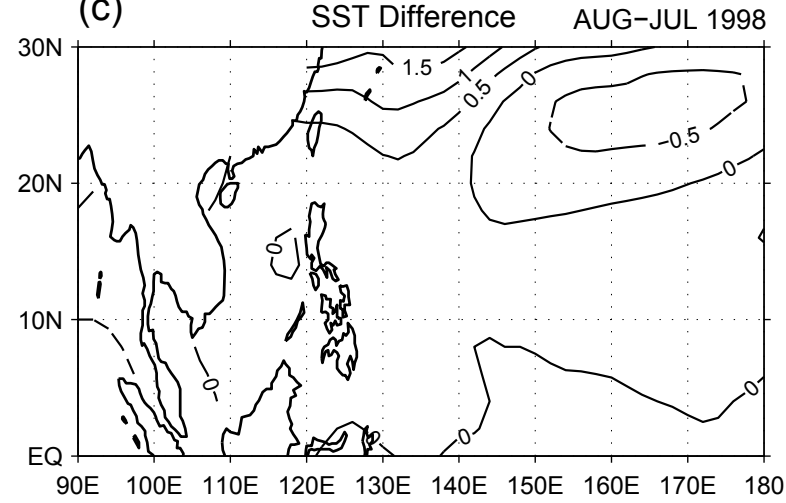

(b)

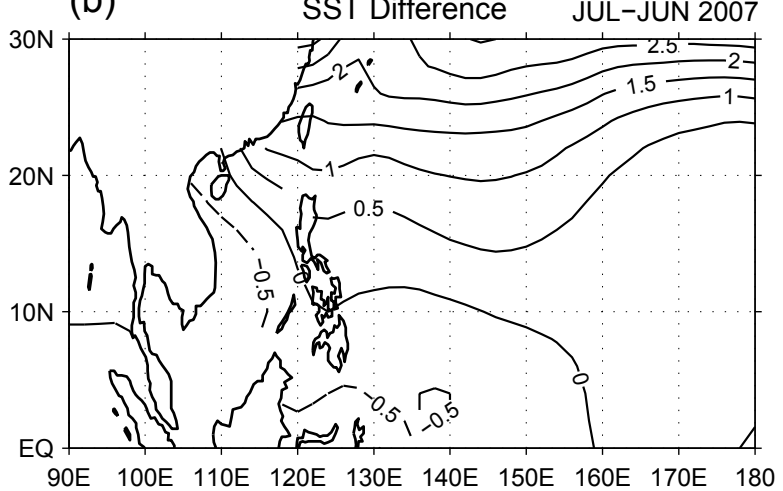

(d)

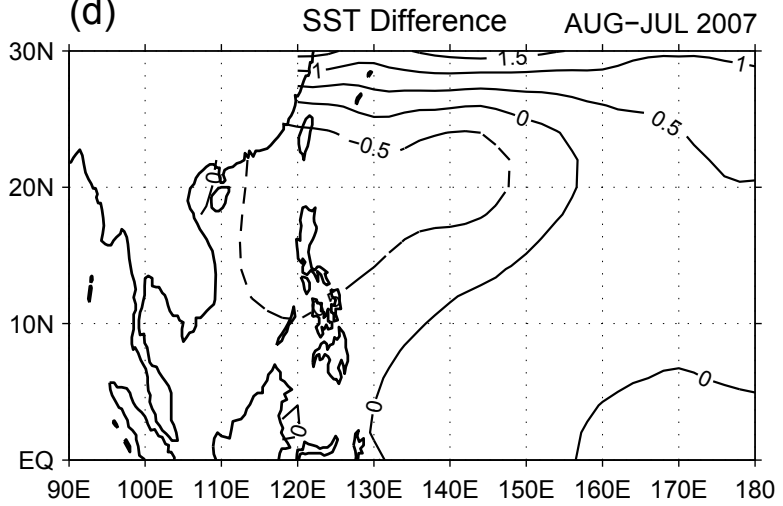

Fig. 15. Monthly sea surface temperature difference (unit: ${ }^{\circ} \mathrm{C}$ ): (a) July minus June in 1998, (b) July minus June in 2007, (c) August minus July in 1998, (d) August minus July in 2007.

\section{August correlation.}

We select 1984 and 2004 as typical examples to further investigate the physical mechanisms for the consistent and significant negative OLR anomalies in June and August. In 1984 and 2004, a higher SST in the preceding spring over the warm pool leads to enhanced convection in the following June, which further induces decreased downward shortwave radiation at the surface and a decreased local SST. As a result, convection in July is suppressed and the solar radiation at the surface tends to rise again together with local SST. Similar to the June convection, the convection in August tends to be enhanced once more. During this process, a consistent anomaly appears over the warm pool in June and August. Clearly, local air-sea interactions play a dominant role in the JuneAugust correlation.

In addition to 1984 and 2004, some other years in Fig. 1 show consistent negative OLR anomalies below a -0.5 standard deviation in June and August (i.e., 1981, 1985, 1986, 1990, 2001, and 2012). Figure
16 further shows the composite OLR anomaly for these years. In general, the composite result shares a common feature with the individual years of 1984 and 2004 in Fig. 7. Negative OLR anomalies appear in June and August and are interrupted by a positive anomaly in July from the South China Sea to the east of the Philippines. However, the significance in July is statistically lower than that in June and August. Combined with the results in 1984 and 2004, we are more confident that the local effect is a major driver in the June-August correlation. By contrast, the anomaly between June and August is not consistent in strong La Niña years, although the warm pool is abnormally warmer in spring. In this case, the warm pool convection is enhanced throughout the summer, with the strongest anomaly in July (Xue and Zhao 2017). Interestingly, the correlation is evident only in the warm pool where deep convective systems are observed. In the equatorial region, however, the OLR anomaly is affected mainly by the ENSO, instead of the local effect. 

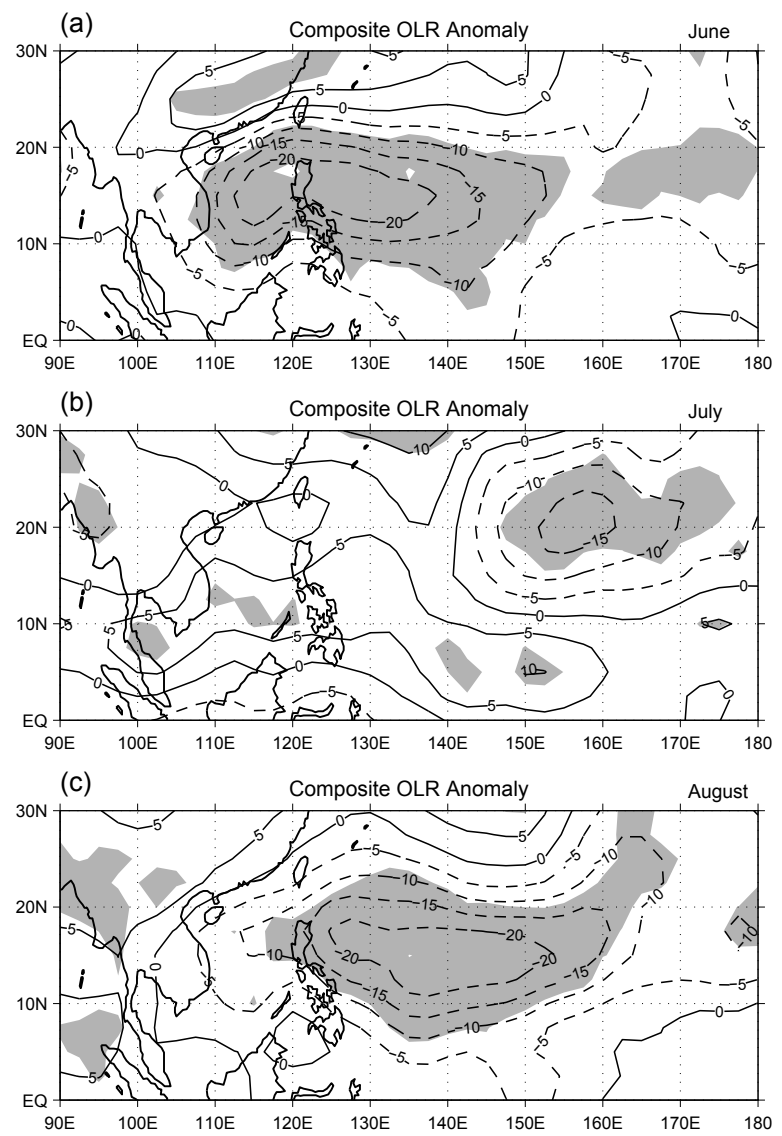

Fig. 16. Composite OLR anomaly (unit: $\mathrm{W} \mathrm{m}^{-2}$ ) for eight years with significant negative OLR anomalies over the warm pool below -0.5 standard deviation (i.e., 1981, 1984, 1985, 1986, 1990, 2001, 2004, and 2012): (a) June, (b) July, (c) August; regions above the $95 \%$ confidence level are shaded.

There is a complex relationship between the JuneAugust convection correlation and El Niño. When the El Niño signal is very strong (e.g., 1998), the consistent positive OLR anomalies induced by the El Niño forcing throughout the summer contribute to the positive convection correlation. When the signal is not so strong (e.g., 2007), positive OLR anomalies during June and July can be attributed to the El Niño forcing. After the forcing weakens in August, the OLR shifts to a negative anomaly due to local air-sea interactions. The combined effects of local and remote factors result in opposite OLR anomalies between June and August. Despite the positive role of the strong El Niño forcing on the correlation, the local effect is the principal reason for the significant positive correlation of convective activity in the warm pool between June and August.

Previous studies have suggested that, as the strongest signal in the tropics, the ENSO plays a crucial role in the warm pool convection and the EASM. The ENSO is also used as a major indicator for the EASM prediction (Xue et al. 2015). When the ENSO signal is not strong, as in 1984 and 2004, the warm pool convection may be enhanced due to local air-sea interactions from a higher SST in the preceding spring. In this case, the WPSH tends to retreat eastward, with less rainfall in eastern China. Additionally, the result provides a reliable signal for the EASM prediction. When the ENSO signal is not strong, the warm pool SST anomaly in spring and the related local air-sea interactions should be given more attention, so that the EASM prediction can be improved (Duan et al. 2008; Lau and Nath 2009).

The results presented in this study show an approximate feature of the warm pool convection associated with local air-sea interactions, based on monthly mean data. It is apparent that we must delineate the interactions between the warm pool convection and SST in more detail using daily data. Moreover, a numeral simulation using an air-sea coupled model is also essential to further reveal the physical mechanism causing this correlation.

\section{Acknowledgments}

The authors appreciate the comments and suggestions from the two anonymous reviewers and the editor Dr. Hiroaki Miura. This study is supported by the National Science Foundation of China (Grant No. 41475052 and 41630530).

\section{References}

Ding, Y. H., and Y. Liu, 2001: Onset and the evolution of the summer monsoon over the South China Sea during SCSMEX field experiment in 1998. J. Meteor. Soc. Japan, 79, 255-276.

Duan, A., C. Sui, and G. Wu, 2008: Simulation of local air-sea interaction in the great warm pool and its influence on Asian monsoon. J. Geophys. Res., 113, D22105, doi:10.1029/2008JD010520.

$\mathrm{Hu}, \mathrm{W}$., and R. Wu, 2016: Air-sea interaction in association with monthly anomaly departure over the western North Pacific and tropical Indian Ocean during the spring-to-summer transition. J. Climate, 29, 20952108.

Kanamitsu, M., W. Ebisuzaki, J. Woollen, S.-K. Yang, J. J. Hnilo, M. Fiorino, and G. L. Potter, 2002: NCEPDOE AMIP-II reanalysis (R-2). Bull. Amer. Meteor. Soc., 83, 1631-1643. 
Lau, K.-M., and S. Yang, 1997: Climatology and interannual variability of the southeast Asian summer monsoon. Adv. Atmos. Sci., 14, 141-162.

Lau, N.-C., and M. J. Nath, 2000: Impact of ENSO on the variability of the Asian-Australian monsoons as simulated in GCM experiments. J. Climate, 13, 42874309.

Lau, N.-C., and M. J. Nath, 2009: A model investigation of the role of air-sea interaction in the climatological evolution and ENSO-related variability of the summer monsoon over the South China Sea and western North Pacific. J. Climate, 22, 4771-4792.

Liebmann, B., and C. A. Smith, 1996: Description of a complete (interpolated) outgoing longwave radiation dataset. Bull. Amer. Meteor. Soc., 77, 1275-1277.

Lu, R., 2001a: Interannual variability of the summertime North Pacific subtropical high and its relation to atmospheric convection over the warm pool. J. Meteor. Soc. Japan, 79, 771-783.

Lu, R., 2001b: Atmospheric circulations and sea surface temperatures related to the convection over the western Pacific warm pool on the interannual scale. $A d v$. Atmos. Sci., 18, 270-282.

Lu, R., and S. Lu, 2014: Local and remote factors affecting the SST-precipitation relationship over the western North Pacific during summer. J. Climate, 27, 51325147.

Nitta, T., 1987: Convective activities in the tropical western Pacific and their impact on the Northern Hemisphere summer circulation. J. Meteor. Soc. Japan, 65, 373390.

Smith, T. M., R. W. Reynolds, T. C. Peterson, and J. Lawrimore, 2008: Improvements to NOAA's historical merged land-ocean surface temperature analysis (1880-2006). J. Climate, 21, 2283-2296.

$\mathrm{Su}, \mathrm{T}$., and F. Xue, 2010: The intraseasonal variation of summer monsoon circulation and rainfall in East Asia. Chinese J. Atmos. Sci., 34, 611-628 (in Chinese).
Tao, S. Y., and L. X. Chen, 1987: A review of recent research on the East Asian summer monsoon in China. Monsoon Meteorology. Chang, C.-P., and T. N. Krishnamurti. (eds.), Oxford University Press, 60-92.

Tsuyuki, T., and K. Kurihara, 1989: Impact of convective activity in the western tropical Pacific on the East Asian summer circulation. J. Meteor. Soc. Japan, 67, 231-247.

Ueda, H., T. Yasunari, and R. Kawamura, 1995: Abrupt seasonal change of large-scale convective activity over the western Pacific in the northern summer. J. Meteor. Soc. Japan, 73, 795-809.

Wu, R., 2002: Processes for the northeastward advance of the summer monsoon over the western North Pacific. J. Meteor. Soc. Japan, 80, 67-83.

Wu, B., T. Li, and T. Zhou, 2010: Relative contributions of the Indian Ocean and local SST anomalies to the maintenance of the western North Pacific anomalous anticyclone during the El Niño decaying summer. $J$. Climate, 23, 2974-2986.

Xie, S.-P., K. Hu, J. Hafner, H. Tokinaga, Y. Du, G. Huang, and T. Sampe, 2009: Indian Ocean capacitor effect on Indo-western Pacific climate during the summer following El Niño. J. Climate, 22, 730-747.

Xue, F., Q. Zeng, R. Huang, C. Li, R. Lu, and T. Zhou, 2015: Recent advances in monsoon studies in China. Adv. Atmos. Sci., 32, 206-229.

Xue, F., and J.-J. Zhao, 2017: Intraseasonal variation of the East Asian summer monsoon in La Niña years. Atmos. Oceanic Sci. Lett., 10, 156-161.

Xue, F., X. Dong, and F. Fan, 2018: Anomalous western Pacific subtropical high during El Niño developing summer in comparison with the decaying summer. Adv. Atmos. Sci., 35, 360-367.

Yang, J., Q. Liu, S.-P. Xie, Z. Liu, and L. Wu, 2007: Impact of the Indian Ocean SST basin mode on the Asian summer monsoon. Geophys. Res. Lett., 34, L02708, doi:10.1029/2006GL028571. 